\section{The clinical utility of gene testing for Alzheimer's disease}

\author{
Emily R. Atkins, Peter K. Panegyres \\ Neurodegenerative Disorders Research, \\ Subiaco, Australia
}

\section{Abstract}

Alzheimer's disease (AD) is the largest cause of dementia, affecting 35.6 million people in 2010. Amyloid precursor protein, presenilin 1 and presenilin 2 mutations are known to cause familial early-onset $\mathrm{AD}$, whereas apolipoprotein E (APOE) $\varepsilon 4$ is a susceptibility gene for late-onset $\mathrm{AD}$. The genes for phosphatidylinositol-binding clathrin assembly protein, clusterin and complement receptor 1 have recently been described by genome-wide association studies as potential risk factors for lateonset AD. Also, a genome association study using single neucleotide polymorphisms has identified an association of neuronal sortilin related receptor and late-onset $\mathrm{AD}$. Gene testing, and also predictive gene testing, may be of benefit in suspected familial early-onset $\mathrm{AD}$ however it adds little to the diagnosis of lateonset $\mathrm{AD}$ and does not alter the treatment. We do not recommend APOE \&4 genotyping.

\section{Introduction}

Alzheimer's Disease International estimates that in 201035.6 million people will have dementia. 1 Alzheimer's disease (AD), a disease first described by Alois Alzheimer in 1906, is the largest cause of dementia. ${ }^{2,3} \mathrm{AD}$ typically affects those aged over 65 years (late-onset AD) but can also affect those younger than 65 years (early-onset AD).4,5 $\mathrm{AD}$ is an insidious neurodegenerative disease, beginning with self-reported short-term memory problems and progressing until total loss of cognitive function and death. ${ }^{2}$ Current AD medications have a minor symptomatic effect and do not prevent its progression. The brains of $\mathrm{AD}$ patients are characterized by extracellular plaques of amyloid-beta $(\mathrm{A} \beta)$ and intracellular neurofibrillary tangles containing hyperphosphorylated tau protein. ${ }^{6}$ The process by which these plaques and tangles cause $\mathrm{AD}$ is not perfectly understood, however three genes were identified to be involved in familial early-onset $\mathrm{AD}$ in the mid-1990s, namely amyloid precursor protein (APP) and the presenilins (PSEN1 and PSEN2) (Table 1).6,7 Mutations in these genes only account for a very small percentage of $\mathrm{AD}$ patients, ${ }^{4}$ and the search for other potential causes of $\mathrm{AD}$ continued. The apolipoprotein $\mathrm{E}$
(APOE) $\varepsilon 4$ allele has been identified as a major risk factor for the development of lateonset $\mathrm{AD}$, but not all those who possess the allele develop $\mathrm{AD}$ and not all who have $\mathrm{AD}$ possess the allele. ${ }^{4} \mathrm{~A}$ genome association study using single neucleotide polymorphisms (SNPs) has identified an association of neuronal sortilin related receptor (SORL1) and late onset $\mathrm{AD} .{ }^{8}$ More recently genome-wide association studies (GWAS) have identified some novel genes associated with AD: clusterin (CLU), complement receptor 1 (CR1), and phosphatidylinositol-binding clathrin assembly protein (PICALM).3,6,7 This paper will examine the clinical utility of genetic testing in $\mathrm{AD}$ in light of recent discoveries.

\section{Familial early-onset Alzheimer's disease}

Familial early-onset AD is a very rare disease which occurs when a highly penetrant gene mutation is inherited in an autosomal dominant pattern. As mentioned above, mutations in APP, PSEN1, and PSEN2 have been identified as causes of familial early-onset AD. ${ }^{4}$ Genetic testing may be of benefit in this situation as the identification of the specific mutation in affected family members will confirm the diagnosis of familial early onset AD. ${ }^{4}$ A similar, and well established, example of an autosomal dominant neurodegenerative disorder is Huntington's Disease (HD). Research conducted with HD families is the basis for many of the recommendations regarding genetic testing for autosomal dominant neurodegenerative disorders. ${ }^{4}$ As with $\mathrm{HD}$, predictive gene testing may be requested by unaffected family members in a familial early-onset $\mathrm{AD}$ as knowledge of carrier status may have implications for reproduction. ${ }^{4}$ Furthermore, preimplantation genetic diagnosis may be an option if a known carrier would like to ensure they do not pass the mutation onto future offspring. 4 At least one instance of this has been reported in the literature, with a healthy child born. ${ }^{10}$

\section{Late-onset Alzheimer's disease}

Late-onset AD is the most common form of $\mathrm{AD}$, and is usually sporadic. However, as already mentioned, some alleles have been identified to increase the risk of developing late-onset $\mathrm{AD}$. $\mathrm{APOE} \varepsilon 4$ is a well-established risk factor for $\mathrm{AD}$, and is associated with a four-fold risk of developing the disease.4-6,11 Since 2007 a number of GWAS have been performed confirming that APOE $\varepsilon 4$ is the most significant gene associated with late-onset AD.12-14 0ther identified genes have only a small effect on the risk of developing AD. SORL1 has been associated with late-onset AD through using SNPs, and PICALM, CLU, and CR1 have recently been identified by GWAS as novel risk factor loci.3,6-8,13,14 GRB2-associated
Correspondence: Peter K. Panegyres, Neurodegenerative Disorders Research Pty Ltd 185 York Street, Subiaco, Western Australia 6008.

Tel.+61 863802255 - Fax: +61.8.6380.2055.

E-mail: publications@panegyres.com.au

Key words: Alzheimer's disease, gene testing.

Received for publication: 27 October 2010.

Revision received: 22 January 2011.

Accepted for publication: 28 March 2011.

This work is licensed under a Creative Commons Attribution 3.0 License (by-nc 3.0).

(O) Copyright E.R. Atkins and P.K. Panegyres, 2011 Licensee PAGEPress, Italy

Neurology International 2011; 3:e1

doi:10.4081/ni.2011.e1

binding protein 2(GAB2), bridging integrator 1 (BIN1), exocyst component 3-like 2 (EXOC3L2) and methylenetetrahydrofolate dehydrogenase (NAPD+ dependent) 1-like (MTHFD1L) have been identified as associated with the development of $\mathrm{AD}$, but have been replicated with mixed results. ${ }^{15-17}$ Other possible $\mathrm{AD}$ genes can be found online (www.molgen.ua.ac.be/ADMutations and www.alzgene. org).

Unlike familial early-onset $\mathrm{AD}$, the presence of these genes does cause $\mathrm{AD}$, but are rather susceptibility genes. Whilst genetic testing can readily identify the presence or absence of these susceptibility genes, this is of little clinical or diagnostic benefit.4,18 A patient may carry the APOE $\varepsilon 4$ allele and not develop AD, or may develop AD without the APOE $\varepsilon 4$ allele. 19

\section{Recommendations for gene testing in Alzheimer's disease}

\section{Diagnosis of Alzheimer's disease}

The diagnosis of $\mathrm{AD}$ can be difficult and clinical expertise is required to distinguish it from other neurodegenerative disorders. Appropriate clinical guidelines, modified in the modern era and including clinical history, neurological examination, imaging in the form of MRI and PET, and genetic testing in appropriate individuals, should be followed. ${ }^{20,21}$ Currently, the diagnosis of AD should not rely solely on genetic testing, but should rather be built from a number of resources.

\section{Familial early-onset Alzheimer's disease}

A positive family history of early-onset $\mathrm{AD}$ with an autosomal dominant inheritance pattern is strongly suggestive of familial earlyonset AD. A patient with suspected familial early onset $\mathrm{AD}$ should be referred to a clinician with an interest in familial dementia and experience in genetic neurodegenerative disorders to confirm the diagnosis. ${ }^{4}$ Genetic testing may be carried out, with the patient's permission, to determine if there are mutations in APP, 
PSEN1, or PSEN2 which would confirm the diagnosis of familial early-onset AD.4,9 If a demented person has a PSEN1 mutation and has a MRI scan that is supportive, then the diagnosis is $\mathrm{AD}$. DNA banking, for future analysis, should be provided as an option for those who do not currently want a test or those who may lack a known mutation. 4

Predictive gene testing for mutations in APP, PSEN1, or PSEN2 in healthy adults should be conducted in a setting of adequate genetic counseling and confidentiality. This should consist of counseling regarding the purpose of performing testing, the meaning of positive or negative results, the implication of results for the patient and their family, alternative options, the benefits and risks, and reassurance that care will not be withdrawn as a result of not undergoing testing. ${ }^{4,9}$ Despite the lack of a cure for familial early-onset $\mathrm{AD}$, there are some benefits to undergoing predictive gene testing. These include life-planning (e.g. whether or not to reproduce) and social planning (e.g. financial and social support).$^{4,9}$ The risks of predictive gene testing include depression, disruption to family and breach of confidentiality, which could lead to social stigmatization, job or health insurance loss in those found to have the mutation. ${ }^{9}$ For those without a mutation the risks include depression and survivor's guilt. ${ }^{9}$ Genetic information is both inherently individual and also shared by a family; therefore there may be some dilemmas when one individual would like to undergo predictive gene testing when their parent or monozygotic twin does not wish to know their genetic status. ${ }^{4,9}$ It is best that an agreement be reached through adequate counseling; however if agreement cannot be reached then predictive gene testing should be carried out provided the parent or twin has time to protect against inadvertently learning the outcome. ${ }^{9}$

\section{Late-onset Alzheimer's disease}

For patients with sporadic late-onset $\mathrm{AD}$ genetic testing for APOE $\varepsilon 4$, SORL1, CLU, CR1, or PICALM is not recommended as it does not provide clinically useful information. These risk factor genes do not improve the sensitivity of specificity of the diagnosis, nor do they alter the treatment.4,18 Predictive gene testing for these risk factor genes is also not recommended as there is currently no potential for prevention or early-intervention. Knowledge of APOE $\varepsilon 4$ status in adults with a parent with Alzheimer's disease did not result in significant short-term psychological distress according to the REVEAL study conducted by Green and colleagues. ${ }^{22}$ However research conducted by Chilibeck and colleagues demonstrates that this knowledge is assimilated into pre-existing beliefs about family susceptibility and the complexity of disease causation. ${ }^{23}$ Furthermore, knowledge of the absence of APOE $\varepsilon 4$ did not dissuade some from the belief that they will develop AD.23 Patients already have their own beliefs of their susceptibility and knowledge of genetic risk, delivered with counseling, does not profoundly change their beliefs. ${ }^{23}$ This illustrates that there is little benefit to knowledge of APOE $\varepsilon 4$. After all, a lack of risk factor genes holds no guarantee that the individual will not develop late-onset $\mathrm{AD}$ and conversely the presence holds no guarantee the individual will develop the disease.

\section{Education, counseling and support}

As always, genetic testing should be carried out in a setting of confidentiality, education, counseling, and support from a multidisciplinary team with expertise in genetic neurodegenerative disorders. ${ }^{4,9}$ The patient and their family should understand the risks and benefits, their alternative options and the implications of the results. ${ }^{4,9}$ In the instance that the patient is demented to the extent that they are unable to give informed consent and family members are not united in the decision to undergo genetic testing, then it should not be performed until a consensus is reached. Genetic counseling, as part of multidisciplinary care, should be provided to assist resolution.

\section{Laboratory accreditation and DNA result disclosure}

DNA testing for patients with suspected AD should always take place in an appropriately accredited laboratory. Whilst the accreditation requirements vary in each nation, the testing should be carried out in a reputable laboratory with quality controls in place to ensure accuracy.4,9,24 The US NIH Genetic Testing Registry, which is expected to become operational in the near future, will address the utility and availability of genetic tests and make this information publicly available, however it will be relying on genetic testing providers to voluntarily submit information. ${ }^{25}$ The success of this registry will become evident in time. Direct to consumer (DTC) genetic testing is not recommended for either familial $\mathrm{AD}$ or sporadic $\mathrm{AD}$ gene testing. As a result of a report from the US Government Accountability off ice, the US Food and Drug Administration has recently notified a number of DTC service providers that their products meet the definition of a medical device based on the manufacturer's claims about test results, and therefore now need to be proven to be safe, accurate and effective. ${ }^{26,27}$ Up to now these tests had been unregulated and alarmingly one manufacturer had planned to make their test available through a pharmacy chain. ${ }^{26}$ The risks of DTC genetic testing lie in decision making as a result of the genetic test. ${ }^{9,26}$ Also there have been instances of consumers receiving results belonging to someone else. ${ }^{28}$ This highlights the importance of laboratory regulation and
Table 1. The genes associated with familial and sporadic Alzheimer's disease.

\begin{tabular}{cc} 
Familial & Sporadic \\
APP & APOE $\varepsilon 4$ \\
PSEN 1 & CLU \\
\hline PSEN 2 & CR1 \\
& PICALM \\
\hline & SORL1 \\
\hline
\end{tabular}

genetic counseling as part of the testing process. To ensure confidentiality, the results of genetic testing should go directly to the clinician who requested the test. 4 They can then be delivered to the patient and their carer under strict confidence, with assistance from genetic counselors. ${ }^{4,9}$ These counselors should continue follow-up with the patient to reduce the risk of adverse reactions, such as psychiatric hospitalization and suicide attempts. ${ }^{4}$ This method as has been successful with Huntington's disease. ${ }^{29}$

\section{Conclusions}

Genetic testing has a role in the diagnosis of familial early-onset $\mathrm{AD}$, however it adds little to the diagnosis of sporadic AD. The use of predictive gene testing for people at risk of familial early-onset $\mathrm{AD}$ may be beneficial, however it is not recommended for risk-factor genes, including APOE $\varepsilon 4$, particularly as there is no known preventative or curative measure available. Any genetic testing should always be conducted in a setting of adequate genetic counseling in a regulated and reputable laboratory. Confidentiality of results should always be assured to the patient.

\section{References}

1. Alzheimer's Disease International. World Alzheimer Report. 2009; available from: http://www.alz.co.uk/research/worldreport/

2. Mayeux R. Early Alzheimer's disease. N Engl J Med 2010;362:2194-201.

3. Skotte N. Genome-wide association studies identify new interesting loci for lateonset Alzheimer's disease. Clin Genet 2010; 77:330-2.

4. Panegyres PK, Goldblatt J, Walpole I, et al. Genetic testing for Alzheimer's disease. Med J Aust 2000;172:339-43.

5. Guerreiro RJ, Gustafson DR, Hardy J. The genetic architecture of Alzheimer's disease: Beyond APP, PSENs and APOE. Neurobiol Aging 2010 Jun 29. [Epub ahead of print]

6. Bettens K, Sleegers K, Van Broeckhoven C. 
Current status on Alzheimer disease molecular genetics: from past, to present, to future. Hum Mol Genet 2010;19:R4-R11.

7. Bertram L, Tanzi RE. Genome-wide association studies in Alzheimer's disease. Hum Mol Genet 2009;18:R137-R45.

8. Rogaeva E, Meng Y, Lee JH, et al. The neuronal sortilin-related receptor SORL1 is genetically associated with Alzheimer disease. Nat Genet 2007;39:168-77.

9. Wertz DC, Fletcher JC, Berg K. Review of ethical issues in medical genetics. World Health Organisation, 2003; available from: http://www.whoint/genomics/publications/en/ethical_issuesin_medgenetics\%20report.pdf

10. Verlinsky Y, Rechitsky S, Verlinsky 0, et al. Preimplantation diagnosis for early-onset Alzheimer disease caused by V717L mutation. JAMA 2002;287:1018-21.

11. Bertram L, Lill CM, Tanzi RE. The genetics of Alzheimer disease: Back to the future. Neuron 2010;68:270-81.

12. Coon KD, Myers AJ, Craig DW, et al. A high-density whole-genome study reveals that APOE is the major susceptibility gene for sporadic late-onset Alzheimer's disease. J Clin Psychiatry 2007;68:613-18.

13. Harold D, Abraham R, Hollingworth P, et al. Genome-wide assocciation study identifies variants at CLU and PICALM associated with Alzheimer's disease. Nat Genet 2009;41:1088-93.

14. Lambert JC, Heath S, Even G, et al. Genome-wide association study identifies variants at CLU and CR1 associated with Alzheimer's disease. Nat Genet 2009;41:
1094-9.

15. Naj AC, Beecham GW, Martin ER, et al. Dementia revealed: Novel chromosome 6 locus for late-onset Alzheimer disease provides genetic evidence for folate-pathway abnormalities. PLoS Genet 2010;6: e10011130.

16. Reiman EM, Webster JA, Myers AJ, et al. GAB2 alleles modify Alzheimer's risk in APOE epsilon4 carriers. Neuron 2007; 54:713-20.

17. Seshadri S, Fitzpatrick AL, Ikram MA, et al. Genome-wide analysis of genetic loci associated with Alzheimer disease. JAMA 2010;303:1832-40.

18. Holston EC, Schutte DL. The clinical utility of genetic information in the care of persons with Alzheimer's disease. Medsurg Nurs 2004;13:415-9.

19. Mayeux R, Saunders AM, Shea S, et al. Utility of the apoliprotein $\mathrm{E}$ genotype in the diagnosis of Alzheimer's disease. $\mathrm{N}$ Engl J Med 1998;338:506-511.

20. Dubois B, Feldman HH, Jacova C, et al. Research criteria for the diagnosis of Alzheimer's disease: revising the NINCDS-ADRDA criteria. Lancet Neurol 2007;6:734-46.

21. Hort J, O'Brien JT, Gainotti G, et al. EFNS guidelines for the diagnosis and management of Alzheimer's disease. Eur J Neurol 2010;17:1236-48.

22. Green RC, Roberts JS, Cupples LA, et al. Disclosure of APOE genotype for risk of Alzheimer's disease. N Engl J Med 2009; 361:245-54.

23. Chilibeck G, Lock M, Sehdev M.
Postgenomics, uncertain futures, and the familiarization of susceptibility genes. Social Science and Medicine. 2010; DOI 10.1016/j.socscimed.2010.01.053.

24. World Health Organisation. Quality and safety in genetic testing: an emerging concern. 2010. Available from: http://www.who.int/genomics/policy/quality_safety/en/print.html

25. National Center for Biotechnology Information (US). Questions and answers: genetic testing registry. 2010; available from: http:/www.ncbi.nlm.nih.gov/gtr/qa/

26. Food and Drug Administration (US). Direct-to-consumer genetic testing and the consequences to the public. 2010 . Available from: http://www.fda.gov/ NewsEvents/Testimony/ucm219925.htm

27. Government Accountability Office (US). Direct-to-consumer genetic tests: misleading test results are further complicated by deceptive marketing and other questionable practices. 2010; Available from: http//www. gao.gov/highlights/d10847thigh.pdf

28. MacArthur D. Sample swaps at 23andMe: a cautionary tale. Genetic Future 2010; Available from: http://scienceblogs.com/ geneticfuture/2010/06/sample_swaps_at_ 23andme_a_caut.php

29. Almqvist EW, Bloch M, Brinkman R, et al. A worldwide assessment of the frequency of suicide, suicide attempts, or psychiatric hospitalization after predictive testing for Huntington Disease. Am J Hum Genet 1999;64:1293-304. 